УДК 339.138:654

Е. В. Болданова

Байкальский государственный университет, г. Иркутск, Российская Федеращия

\title{
ТЕНДЕНЦИИ В МИРОВЫХ ТЕЛЕКОММУНИКАЦИЯХ
}

\begin{abstract}
АНнотАция. В данной статье был проведен анализ тенденций, сложившихся на рынке услуг связи последние десятилетия. Были рассмотрены данные более двадцати стран, включая развитые и развивающиеся. В качестве инструментария для исследования был использован корреляционно-регрессионный анализ. Выявлена неактуальность диаграммы Джиппа по проводной телефонной связи. Сделан анализ пиков развития проводной телефонной связи, периодов активного роста сотовой связи, определен уровень зрелости услуги доступа в Интернет. Сделан вывод о спаде проводной телефонной связи, зрелости сотовой связи и доступа в Интернет и росте широкополосного доступа в Интернет. Выявлена общая тенденция всех рассматриваемых стран к общему уровню телекоммуникационной инфраструктуры в условиях глобализации. Сделан вывод о первичности развития инфраструктуры для экономики.
\end{abstract}

кЛючЕВЫЕ словА. Телекоммуникации; сотовая связь; проводная телефонная связь; достУП в Интернет.

ИНФОРМАЦИЯ О СТАТЬЕ. Дата поступления 1 марта 2017 г.; дата принятия к печати 10 марта 2017 г.; дата онлайн-размещения 31 марта 2017 г.

E. V. Boldanova

Baikal State University, Irkutsk, Russian Federation

\section{TRENDS IN WORLD TELECOMMUNICATIONS}

\begin{abstract}
This article analyzes the trends prevailing in the communication service market during the last decades. It considers the data of more than twenty countries, including both developed and developing ones. As a research instrumentation, it uses the correlation-regression analysis. It identifies the out-of-dateness of the Gipp's chart over the wired telephone connection. The article analyses development peaks for the wired telephone connection, periods of active cellular communication growth, determines the maturity level of Internet access services. It makes a conclusion about decline of the wired telephone communication, cellular communication maturity and access to the Internet and growth of the broadband Internet access. It identifies a general trend of all the countries under consideration towards the general level of telecommunication infrastructure in terms of globalization.
\end{abstract}

KEYWORDS. Telecommunications; cellular communication; wired telephone communication; the Internet access.

ARTICLE INFO. Received March 1, 2017; accepted March 10, 2017; available online March 31, 2017.

Современное состояние мировых телекоммуникаций характеризуется значительными темпами роста в области доступа в Интернет и увеличении объема передаваемого трафика.

Традиционные услуги уже прошли свой пик и находятся на этапе зрелости или спада.

Задачей данного исследования является анализ тенденций в телекоммуникациях европейских стран и стран Юго-Восточной Азии. В качестве инструмента исследования используется корреляционно-регрессионный анализ [1, с. 44; 2 , с. 13].

(C) E. В. Болданова, 2017

\section{Baikal Research Journal}

электронный научный журнал Байкальского государственного университета 
Одной из основополагающих тенденций в телекоммуникациях в XX в. была экспоненциальная зависимость телефонной плотности (число проводных телефонов на 100 чел.) от среднедушевого валового внутреннего продукта, получившая название зависимости Джиппа [3, с. $13 ; 4$, с. 92]. Необходимо проверить, актуально ли это в XXI в.

Анализ проводился по данным, полученным с сайта Мирового Банка ${ }^{1}$. В свою очередь Мировой Банк ссылается на Международный союз электросвязи ${ }^{2}$.

Результат анализа по Австрии: проводная телефонная связь прошла свой пик развития и находится в стадии спада (рис. 1).

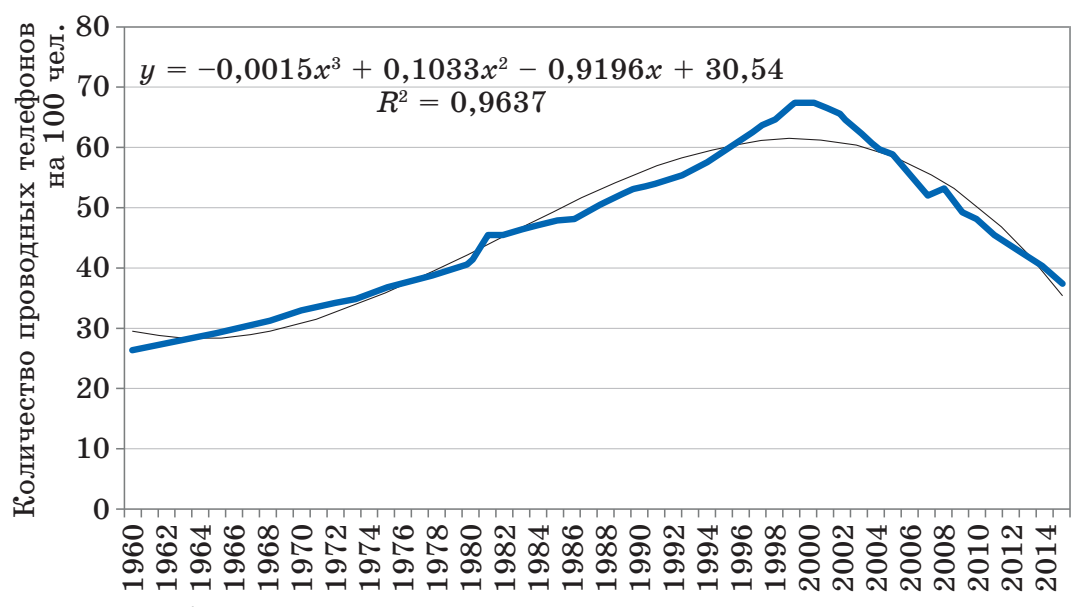

Рис. 1. Динамика телефонной плотности в Австрии

На рис. 1 хорошо видно, что фактические данные аппроксимируются кубической параболой, достаточно часто использующейся для описания жизненного цикла товара. В данном случае фактические данные подтверждают теорию. Интересно заметить, что пик проводной телефонной связи совпал с периодом бурного роста сотовой связи. Хотя это еще предстоит проверить. Кроме того, на графике не отслеживается влияние экономических циклов, которые наблюдаются в экономике страны с периодичностью $8,13,17$ и 29 лет [5, с. 22].

Анализ развития сотовой связи в Австрии приведен на рис. 2.

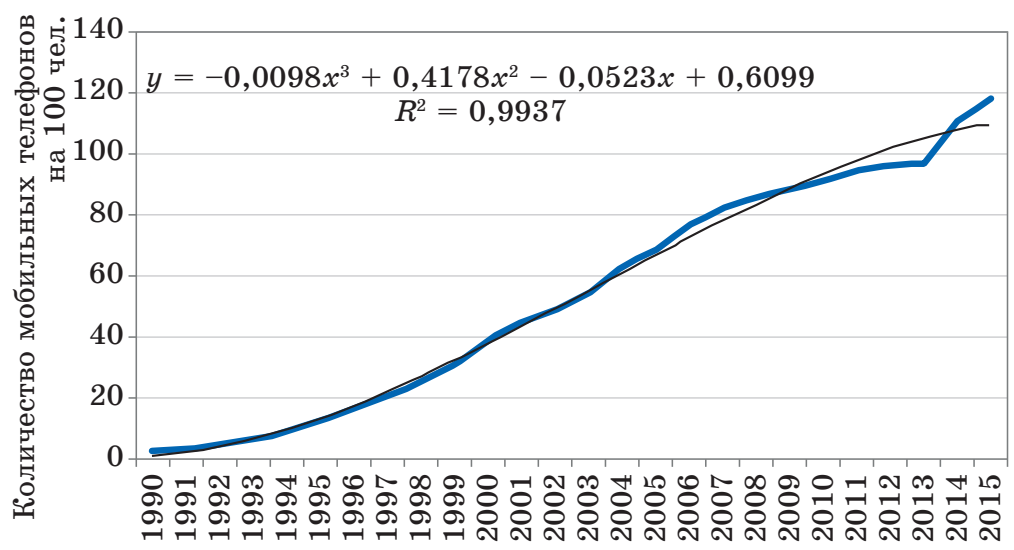

Рис. 2. Динамика проникновения сотовой связи в Австрии

${ }^{1}$ Сайт Мирового Банка. Режим доступа. URL: http://databank.worldbank.org.

${ }^{2}$ Сайт Международного союза элекстросвязи. URL: http://www.itu.int.

\section{Baikal Research Journal}


При сопоставлении этих двух графиков видно, что момент пика проводной связи в 1997-2000 гг. пришелся на период бурного роста сотовой связи. Услуги оказались взаимозаменяемыми, поэтому более новая услуга сотовой связи пришла на смену проводной телефонной связи.

Исследование услуги доступа в Интернет представлено на рис. 3.

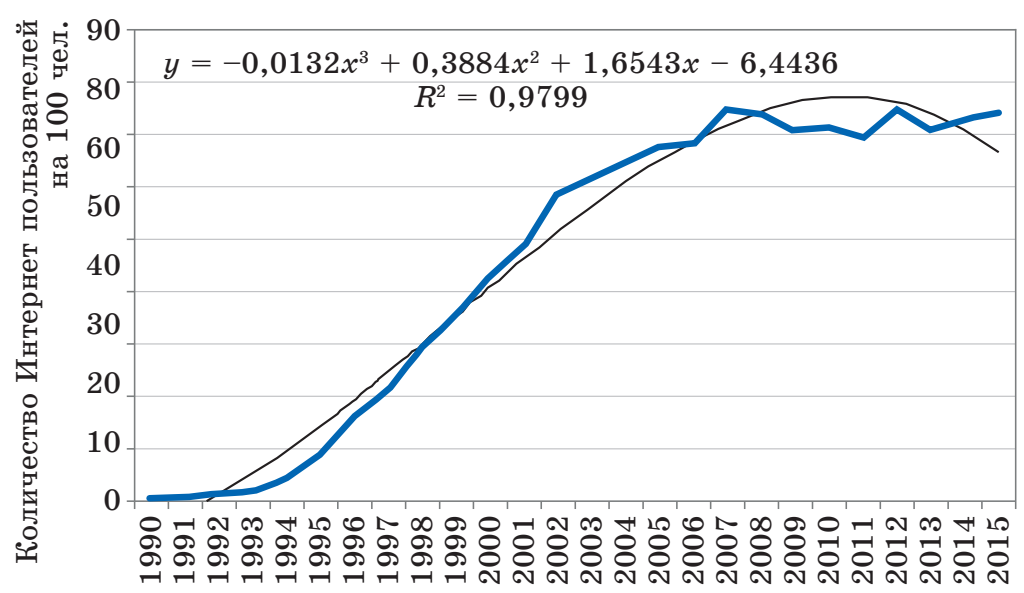

Рис. З. Динамика уровня проникновения доступа в Интернет в Австрии

Из представленного графика видно, что услуга является дополняющей к услуге сотовой связи. И обе эти услуги на сегодняшний момент достигли этапа зрелости. Темпы уровня проникновения значительно снизились или находятся на нулевом уровне.

Какие же услуги электросвязи сегодня находятся на подъеме? Рассмотрим услугу широкополосного доступа в Интернет (ШПДИ) (рис. 4).

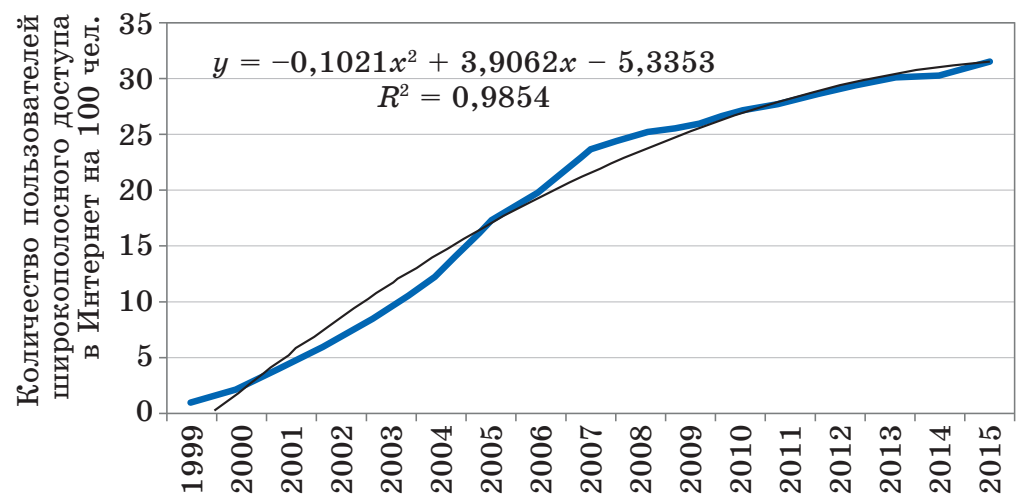

Рис. 4. Динамика проникновения услуги широкополосного доступа в Интернет в Австрии

Для данной услуги, вероятно, еще все впереди. В дальнейшем спрос на услугу ШПДИ будет только расти за счет развития развлекательной сферы: сетевые игры, телевидение высокой четкости, а в будущем - трехмерное телевидение, которое потребует бульших ресурсов.

Как же выглядит диаграмма Джиппа на сегодняшний момент по данным Австрии? Зависимость количества проводных телефонов от среднедушевого валового продукта представлено на рис. 5 .

\section{Baikal Research Journal}




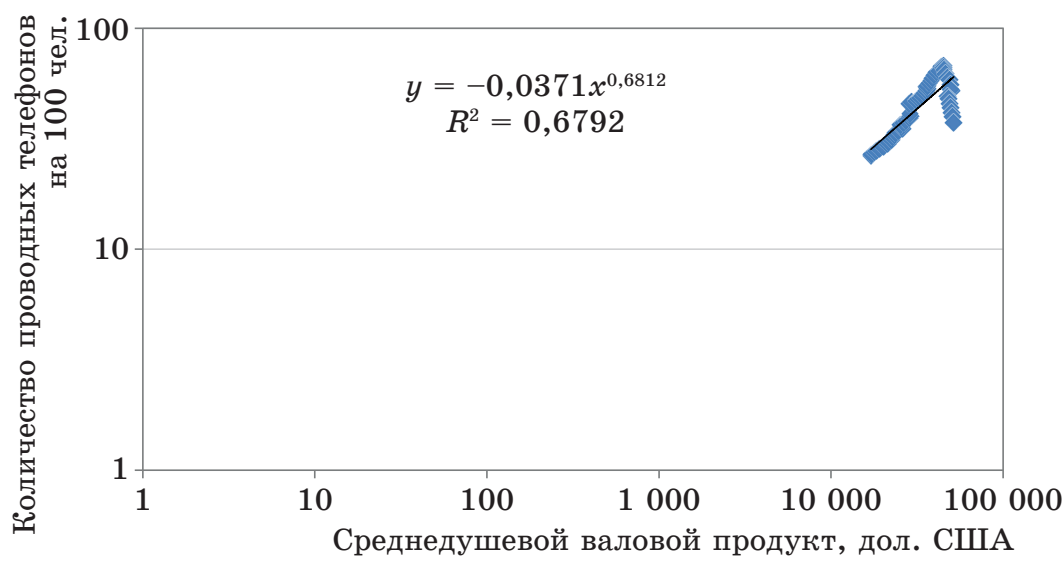

Рис. 5. Диаграмма Джиппа по данным Австрии

Данные использованы с 1960 по 2015 г. Зависимость «сломалась». Необходимо искать другую линию тренда. Наиболее адекватной для этой зависимости является все та же кубическая парабола, или полиномиальная функция третьей степени (рис. 6).

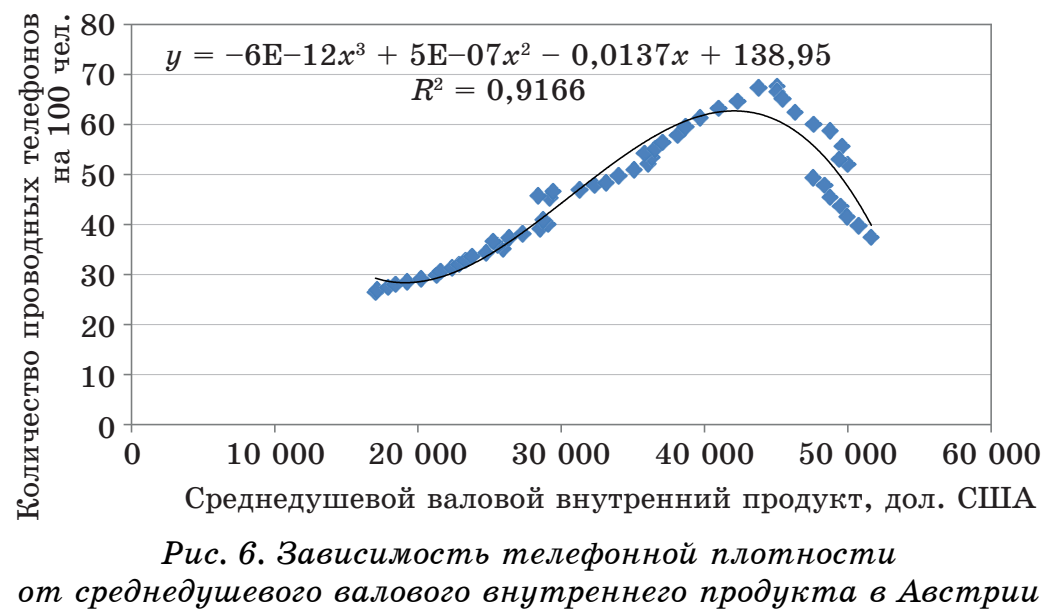

Да, эта линия тренда хорошо подходит, она адекватна и надежна. Но экономического смысла в ней уже нет. Очевидно, что услуга, достигнув этапа спада, уже не зависит от уровня доходов в стране. Здесь действуют уже другие законы. И лучше зависимость Джиппа вообще не использовать в данном случае. Гораздо более продуктивно будет считать, что влияет фактор времени, и зависимость, представленная на рис. 1 более информативна.

Для анализа были оценены корреляционные связи между услугами и среднедушевым валовым внутренним продуктом. ВВП был приведен к уровню 2010 г. для сопоставимости. Проанализированы данные за 1999-2015 гг. Корреляционная матрица приведена в табл. 1.

В анализируемый период наблюдался рост по практически всем услугам, за исключением проводной телефонной связи, а также был рост и среднедушевого валового внутреннего продукта. Поэтому результат очевиден: высокие значения корреляционных связей.

\section{Baikal Research Journal}


Таблица 1

Таблица парных коэффициентов корреляции между услугали связи и среднедушевыл валовым внутреннил продуктол по Австрии

\begin{tabular}{|c|c|c|c|c|c|}
\hline \multirow[t]{2}{*}{ Показатель } & \multicolumn{3}{|c|}{ Количество пользователей на 100 чел. } & \multirow{2}{*}{$\begin{array}{c}\text { Количество } \\
\text { проводных } \\
\text { телефонов } \\
\text { на } 100 \text { чел. }\end{array}$} & \multirow{2}{*}{$\begin{array}{c}\text { Среднедуше- } \\
\text { вой ВВП, дол. } \\
\text { США, уро- } \\
\text { вень } 2010 \text { г. }\end{array}$} \\
\hline & $\begin{array}{l}\text { Сотовой } \\
\text { связи }\end{array}$ & $\begin{array}{c}\text { Широкополос- } \\
\text { ного доступа } \\
\text { к Интернет } \\
\end{array}$ & Интернет & & \\
\hline $\begin{array}{l}\text { Количество пользовате- } \\
\text { лей на } 100 \text { чел. }\end{array}$ & - & - & - & - & - \\
\hline сотовой связи & 1 & - & - & - & - \\
\hline $\begin{array}{l}\text { широкополосного до- } \\
\text { ступа к Интернет }\end{array}$ & 0,981732 & 1 & - & - & - \\
\hline Интернет & 0,979803 & 0,990850 & 1 & - & - \\
\hline $\begin{array}{l}\text { Количество проводных } \\
\text { телефонов на } 100 \text { чел. }\end{array}$ & $-0,916680$ & $-0,946690$ & $-0,938740$ & 1 & - \\
\hline $\begin{array}{l}\text { Среднедушевой ВВП, дол. } \\
\text { США, уровень } 2010 \text { г. }\end{array}$ & 0,955600 & 0,967720 & 0,977838 & $-0,941250$ & 1 \\
\hline
\end{tabular}

Аналогичный анализ был проведен еще по 22 странам. Результаты представлены в сводной таблице (табл. 2).

Таблица 2

Сводные результаты анализа телекоммуникаций

\begin{tabular}{|l|c|c|c|}
\hline \multicolumn{1}{|c|}{ Страна } & $\begin{array}{c}\text { Год пика проводной } \\
\text { телефонной связи }\end{array}$ & $\begin{array}{c}\text { Период быстрого } \\
\text { роста сотовой связи }\end{array}$ & $\begin{array}{c}\text { Стадия зрелости услуги } \\
\text { доступ в Интернет }\end{array}$ \\
\hline Швеция & 1997 & $1993-2000$ & Зрелость \\
\hline Норвегия & 1997 & $1995-2000$ & Зрелость \\
\hline Нидерланды & 1999 & $1997-2000$ & Зрелость \\
\hline Финляндия & 1999 & $1997-2002$ & Зрелость \\
\hline США & 1999 & Нет & Зрелость \\
\hline Великобритания & 2000 & $1997-2000$ & Зрелость \\
\hline Бельгия & 2000 & $1998-2001$ & Зрелость \\
\hline Италия & 2001 & $1996-2001$ & Рост \\
\hline Швейцария & 2001 & $1997-2000$ & Зрелость \\
\hline Дания & 2001 & $1997-2002$ & Зрелость \\
\hline Канада & 2001 & $1998-2004$ & Зрелость \\
\hline Болгария & 2001 & $2001-2005$ & Рост \\
\hline Бразилия & 2001 & $2001-2008$ & Рост \\
\hline Германия & 2004 & $1997-2000$ & Зрелость \\
\hline Греция & 2004 & $1998-2002$ & Рост \\
\hline Индия & 2005 & $2005-2011$ & Рост \\
\hline Китай & 2006 & $2000-2010$ & Рост \\
\hline Испания & 2007 & $1998-2003$ & Рост \\
\hline Мексика & 2007 & $1999-2006$ & Рост \\
\hline Российская Федерация & 2008 & $2003-2006$ & Зрелость \\
\hline Франция & 2009 & $1997-2001$ & Зрелость \\
\hline Япония & Нет & $1995-2003$ & \\
\hline
\end{tabular}

Очевидно, что большинство развитых стран прошли пик в развитии проводной телефонной связи, имели период бурного роста сотовой связи, практически совпавший с пиком проводной телефонии, и имеют услугу доступа в Интернет на этапе зрелости. Широкополосный доступ в Интернет находится в стадии роста.

\section{Baikal Research Journal}


Развивающиеся страны, несмотря на то, что не достигли таких же значений как развитые страны в проводной телефонной связи, практически с небольшим временным лагом достигли такого же уровня сотовой связи. Доступ в Интернет в этих странах находится на этапе роста.

Анализ зависимости числа пользователей ШПДИ на 100 чел. от среднедушевого валового внутреннего продукта показал, что зависимости нет. Сводные данные по всем рассматриваемым странам представлены на рис. 7.

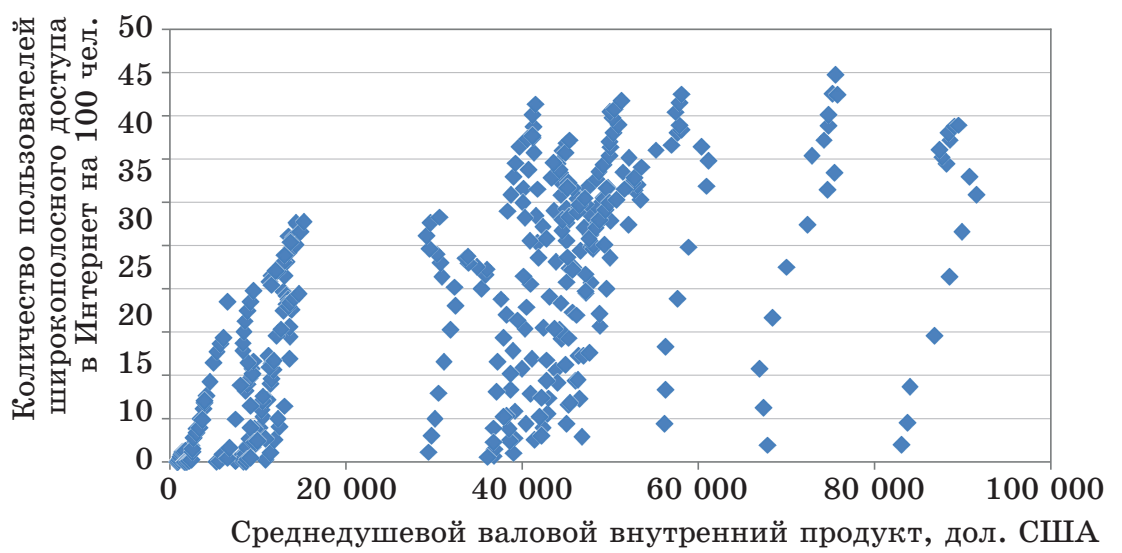

Рис. 7. Анализ зависимости количества пользователей широкополосного доступа в Интернет на 100 чел. от среднедушевого валового внутреннего продукта по рлду стран

Из диаграммы видно, что во всех странах наблюдается рост числа пользователей скоростного Интернета, независимо от уровня благосостояния экономики. Средние значения уровня проникновения этой услуги находятся в пределах 20-45 пользователей на 100 чел.

Данное исследование подтверждает влияние глобализации на развитие телекоммуникаций $[6$, с. 11$]$. Общий уровень развития телекоммуникационной инфраструктуры в различных странах стремится к одним и тем же параметрам: уровень развития сотовой связи и доступа в Интернет. Уровень валового внутреннего продукта уже не имеет такого существенного влияния, как это было в $\mathrm{XX}$ в. с проводной телефонной связью. Не уровень экономики определяет уровень развития телекоммуникаций, а развитие телекоммуникационной инфраструктуры становится необходимым фактором роста экономики, также как и других инфраструктур $[7$, с. $33 ; 8$, с. $130 ; 9$, с. $210 ; 10$, с. 77]. Полученный результат можно использовать при планировании, прогнозировании развития инфраструктуры региона.

\section{Список использованной литературы}

1. Войникова Г. Н. Использование трендовых зависимостей в управлении деятельностью предприятия / Г. Н. Войникова // Проблемные аспекты развития транспортной системы : материалы науч.-практ. конф. с междунар. участием. Иркутск, 18 июня 2015 г. / под ред. Г. В. Давыдовой, Г. Н. Войниковой, А. И. Бирюковой. - Иркутск : Изд-во БГУЭП, 2015. - С. 44-57.

2. Болданова Е. В. Планирование и прогнозирование в телекоммуникациях / Е. В. Болданова. - Иркутск : Изд-во БГУЭП, 2012. - 268 с.

3. Болданова Е. В. Рынок телекоммуникаций / Е. В. Болданова. - Иркутск : Изд-во БГУЭП, 2010. - 220 с.

\section{Baikal Research Journal}


4. Болданова Е. В. Рынок услуг связи : учеб. пособие / Е. В. Болданова. - Иркутск : Изд-во БГУЭП, 2010. - 232 с.

5. Boldanova E. V. Modern Economic Cycles and their Impact on Economy / E. V. Boldanova // North-East Asia Academic Forum. - 2013. - № 1. - C. 22-25.

6. Малецкая М. Б. Российский рынок услуг связи в условиях глобализации [Электронный ресурс] / М. Б. Малецкая // Известия Иркутской государственной экономической академии (Байкальский государственный университет экономики и права). - 2013. № 6. - Режим доступа: http://brj-bguep.ru/reader/article.aspx?id=18654.

7. Бирюкова А. И. Оценка инвестиционной привлекательности региона / А. И. Бирюкова // Проблемные аспекты развития транспортной системы : материалы науч.-практ. конф. с междунар. участием. Иркутск, 18 июня 2015 г. / под ред. Г. В. Давыдовой, Г. Н. Войниковой, А. И. Бирюковой. - Иркутск : Изд-во БГУЭП, 2015. - С. 33-38.

8. Винокуров М. А. Экономика Иркутской области : в 6 т. / М. А. Винокуров, А. П. Суходолов. - Иркутск : Изд-во БГУЭП, 2009. - Т. 6. - 292 с.

9. Транспортное обеспечение Сибири: проблемы и перспективы / В. Б. Игнатьев, Ю. В. Гордина, Я. Л. Горчаков, Е. Ю. Молокова. - Иркутск : Изд-во БГУЭП, 2006. - 310 с.

10. Кородюк И. С. Состояние и перспективы развития транспортного комплекса Иркутской области / И. С. Кородюк // Проблемные аспекты развития транспортной системы : материалы науч.-практ. конф. с междунар. участием. Иркутск, 18 июня 2015 г. / под ред. Г. В. Давыдовой, Г. Н. Войниковой, А. И. Бирюковой. - Иркутск : Изд-во БГУЭП, 2015. - С. $77-84$.

\section{References}

1. Voynikova G. N. Using trend dependences in management of enterprise performance. In Davydova G. V., Voynikova G. N. Biryukova A. I. (eds). Problemnye aspekty razvitiya transportnoi sistemy. Materialy nauchno-prakticheskoi konferentsii s mezhdunarodnym uchastiem. Irkutsk, 18 iyunya 2015 g. [Development Issues of the Transport System. Materials of Research Conference with International Participation, Irkutsk, June 18, 2015]. Irkutsk, Baikal State University of Economics and Law Publ., 2015, pp. 44-57. (In Russian).

2. Boldanova E. V. Planirovanie i prognozirovanie v telekommunikatsiyakh [Planning and forecasting in telecommunications]. Irkutsk, Baikal State University of Economics and Law Publ., 2012. 268 p.

3. Boldanova E. V. Rynok telekommunikatsii [Telecommunication market]. Irkutsk, Baikal State University of Economics and Law Publ., 2010. 220 p.

4. Boldanova E. V. Rynok uslug svyazi [Communication Services Market]. Irkutsk, Baikal State University of Economics and Law Publ., 2010. 232 p.

5. Boldanova E. V. Modern economic cycles and their impact on economy. North-East Asia Academic Forum, 2013, no. 1, pp. 22-25.

6. Maletskaya M. B. The Russian market of communication services in the process of globalization. Izvestiya Irkutskoi gosudarstvennoi ekonomicheskoi akademii (Baykalskii gosudarstvennyi universitet ekonomiki $i$ prava $)=$ Bulletin of Irkutsk State Economics Academy (Baikal State University of Economics and Law), 2013, no. 6. Available at: http://brj-bguep. $\mathrm{ru} /$ reader/article.aspx?id=18654. (In Russian).

7. Biryukova A. I. Assessment of regional investment attractiveness. In Davydova G. V., Voynikova G. N. Biryukova A. I. (eds). Problemnye aspekty razvitiya transportnoi sistemy. Materialy nauchno-prakticheskoi konferentsii s mezhdunarodnym uchastiem, Irkutsk, 18 iyunya 2015 g. [Development Issues of the Transport System. Materials of Research Conference with International Participation, Irkutsk, June 18, 2015]. Irkutsk, Baikal State University of Economics and Law Publ., 2015, pp. 33-38. (In Russian).

8. Vinokurov M. A., Sukhodolov A. P. Ekonomika Irkutskoi oblasti [Economy of Irkutsk Oblast]. Irkutsk, Baikal State University of Economics and Law Publ., 2009. Vol. 6. 292 p.

9. Ignatyev V. B., Gordina Yu. V., Gorchakov Ya. L., Molokova E. Yu. Transportnoe obespechenie Sibiri: problemy i perspektivy [Transport provision of Siberia: problems and prospects]. Irkutsk, Baikal State University of Economics and Law Publ., 2006. 310 p.

10. Korodyuk I. S. State and prospects of transport complex development in Irkutsk Oblast. In Davydova G. V., Voynikova G. N. Biryukova A. I. (eds). Problemnye aspekty raz-

\section{Baikal Research Journal}


vitiya transportnoi sistemy. Materialy nauchno-prakticheskoi konferentsii s mezhdunarodnym uchastiem, Irkutsk, 18 iyunya 2015 g. [Development Issues of the Transport System. Materials of Research Conference with International Participation, Irkutsk, June 18, 2015]. Irkutsk, Baikal State University of Economics and Law Publ., 2015, pp. 77-84. (In Russian).

\section{Информация об авторе}

Болданова Елена Владилировна - кандидат экономических наук, доцент, кафедра экономики и управления бизнесом, Байкальский государственный университет, 664003, г. Иркутск, ул. Ленина, 11; e-mail: boldanova@bk.ru.

\section{Author}

Elena V. Boldanova - PhD in Economics, Associate Professor, Chair of Economics and Business Management, Baikal State University, 11 Lenin St., 664003, Irkutsk, Russian Federation; e-mail: boldanova@bk.ru.

\section{Библиографическое описание статьи}

Болданова Е. В. Тенденции в мировых телекоммуникациях / Е. В. Болданова // Baikal Research Journal. - 2017. — T. 8, № 1. — DOI: 10.17150/2411-6262.2017.8(1).11.

\section{Reference to article}

Boldanova E. V. Trends in world telecommunications. Baikal Research Journal, 2017, vol. 8, no. 1. DOI: 10.17150/2411-6262.2017.8(1).11. (In Russian).

\section{Baikal Research Journal}

